\title{
Hydromechanical analysis of masonry gravity dams and their foundations
}

\author{
Eduardo M. Bretas ${ }^{1}$, José V. Lemos ${ }^{2}$, Paulo B. Lourenço ${ }^{3}$
}

1. Eduardo M. Bretas (corresponding author): Postdoctoral Researcher, National Laboratory for Civil Engineering, Av. do Brasil, 101, 1700-066, Lisbon, Portugal, Email: ebretas@lnec.pt, Phone: (351) 218443 985, Fax: (351) 218443026

2. José V. Lemos: Researcher, National Laboratory for Civil Engineering, E-mail: vlemos@lnec.pt

3. Paulo B. Lourenço: ISISE, University of Minho, Department of Civil Engineering, E-mail: pbl@civil.uminho.pt

\begin{abstract}
A numerical model for the hydromechanical analysis of masonry dams based on the discrete element method is presented. The dam and the rock foundation are represented as block assemblies, and a coupled flow-stress analysis is performed in an integrated manner for the entire system. Complex block shapes may be obtained by assembling elementary blocks into macroblocks, allowing the application of the model to situations ranging from equivalent continuum to fully discontinuum analysis. A contact formulation was developed based on an accurate edge-edge approach, incorporating mechanical and hydraulic behavior. The main numerical aspects are described, with an emphasis in the flow analysis explicit algorithm. An application to an existing masonry dam is presented, analyzing its present condition, with excessive seepage, and the proposed rehabilitation intervention. An evaluation of sliding failure mechanisms was also performed, showing the expected improvement in the safety of the structure.
\end{abstract}

Keywords: Masonry dams, discrete elements, hydromechanical analysis, failure 


\section{Introduction}

Seepage, which takes place through the whole dam-foundation system, is a much relevant phenomenon when assessing the structural safety of dams, particularly in the case of gravity dams. The flow is established primarily in the discontinuities, being almost negligible through the concrete or rock, due to the low permeability of these materials. In the particular case of masonry gravity dams, water flow may occur in the dam body (in cracks or other discontinuities), in the dam-rock interface and through the foundation itself. There were several accidents directly related to this phenomenon, such as the historical accident of Bouzey dam, in 1895, which brought attention to the role of water pressure in dam safety (Bretas et al. 2012).

Seepage is a consequence of the hydraulic gradient imposed by the dam and for this reason cannot be avoided. It is therefore necessary to adopt control measures, such as the grout curtains and the drainage systems. The intensity of the seepage and its effect on the safety of the structure depend fundamentally on the characteristics of the water reservoir, the flow velocity and the stress field established due to the presence of water (ICOLD 1983).

The reservoir water may be too aggressive for mortar and concrete and may thus lead to a progressive degradation of the material by leaching the calcium (Eglinton 1987). This phenomenon is even more evident in masonry dams. It causes a loss of cohesion of the mortar that ensures the continuity of the material, leading to disintegration of masonry (Chatterjee et al. 1991). The chemical action also has a side effect associated with the loss of effectiveness of the drainage system by clogging associated with deposition of calcium carbonate.

The flow rate should not be excessive, since this causes washing of fine particles and an increase in the permeability, with negative long term consequences. The mechanical effect of water in the dam body, in the dam-foundation interface or in the rock mass creates an uplift effect, equivalent to the reduction of the self-weight of the structure (Serafim 1968). Uplift and permeability are correlated because the permeability depends on the stress state in the media. Therefore, changes in the stress state produce changes in the opening of the discontinuities. Moreover, the actual stress condition results from the balance between the various loads involved, including uplift. Therefore, hydromechanical analyzes should allow for the coupling between permeability and stress.

The control of flow and its consequences is done primarily through the grout and the drainage curtains. The uplift reduction depends on the increase of relative permeability, while the flow velocity is a function of absolute permeability. The grout curtain changes the relative permeability, reducing the permeability locally, while the drainage system changes the relative permeability of the media, by increasing permeability locally. Thus, in theory, a grout curtain reduces the uplift and the flow rate, while the drainage reduces the uplift and increases the flow rate (Casagrande 1961). In practice, however, the most 
significant effect of grouting is to reduce the flow velocity, and drains are intended to reduce uplift (Ruggeri 2004). Often, the uplift at the base of the dam is the scenario that raises major concerns, since it influences the overall stability of the structure.

It is important to note that raising the level of the reservoir does not imply a proportional increase in the uplift pressure or amount of drained water, as often this relationship is nonlinear. The increase in the level of the reservoir causes a change of the stress state in the dam-foundation system, particularly at the dam-foundation interface and in the rock mass, and causes the opening or closing of discontinuities, thereby modifying the hydraulic conditions. It remains to note that these changes take place for a period of time which can be long, even if the change in the reservoir level is relatively fast.

The problem of hydromechanical coupling has been extensively studied. Rutqvist and Stephansson (2003) address the importance of hydromechanical behavior especially in the case of civil engineering works involving shallow zones of rock mass or with low in-situ permeability, both sensitive to stress changes. In the case of hydraulic structures, particularly dams, the coupling issue is even more relevant because it may influence the failure mechanisms. Numerical models are very useful for hydromechanical coupling analysis, since the models can be calibrated according to the monitoring data collected. Depending on the discontinuity pattern, homogeneous models, by means of equivalent continuum techniques, may be appropriate. For example, the finite element model proposed by Erban and Gell (1988) uses a hydraulic model, in parallel to the mechanical model, whose permeability matrix is changed throughout the analysis depending on the stress state of the structure. Continuous models are often insufficient to carry out nonlinear studies in which there is a change in the model geometry and permeability properties, as identified by Lombardi (1992). This includes, for example, sliding along discontinuities in which the dilatancy effect can be important. For this reason, hybrid discrete-continuum models have been used as a valid alternative (e.g. Stematiu 1990, Wei and Hudson 1988). In this approach, the equivalent continuum model is globally employed and the main discontinuities are modeled with the discrete element model.

For highly discontinuous media or media subject to an important hydraulic gradient, discontinuous or discrete models should be used (Soyeaux 1990). Cammarata et al. (2007) proposed a 2D BEM-FEM formulation to model the flow in a fracture network, which was applied to the transient analysis of fluid injection in a single fracture. Gimenes and Fernández (2006) describe a calibration methodology for a concrete gravity dam model, analyzed with UDEC (Itasca 2011). Another example of the use of UDEC for the hydromechanical analysis of gravity dam foundations was presented by Barla et al. (2004), comparing the influence of deterministic or random joint patterns. These authors show the benefits of using numerical models to compute the uplift pressure distribution along the dam base, with or without grout curtain and drainage, based upon the data available for the rock joints and discontinuities. 
The free surface conditions may be important in the seepage analysis of the dam body itself, especially in the case of masonry dams (Char et al. 1991). The gradual deterioration of masonry and the reduction of the initial mechanical properties are the most common effects. These deterioration problems have been identified for long (e.g. Paolina et al. 1991). Rehabilitation works are usualy carried out to (i) decrease the permeability of the dam, through a grouting program, (ii) to enhance the drainage system, which may include the opening of new drainage galleries (e.g. Bettzieche 2004), and also (iii) to restore imperviousness of the upstream face through the installation of a concrete curtain (e.g. Silveira and Ramos 1994) or, more recently, through the addition of a geomembrane system (e.g. Scuero et al. 2007). In some cases the compliace with current stability standards require also structural reinforcement. One worthy example of this is the solution with vertical prestressed anchors designed for the Eder dam, in Germany (Wittke et al. 2012).

The present paper proposes a unified treatment of the hydromechanical behavior of masonry dams and their rock mass foundations, by means of a newly developed 2D code based on the Discrete Element Method (DEM) (Bretas 2012). An edge-to-edge contact formulation is employed, in contrast with the typical point contact approach used in DEM implementations, which allows a more accurate representation of the stress distribution along joints. The flow analysis is formulated consistently with the mechanical assumptions, as described next. Grout and drainage systems can also be easily included in the model. The case study presented consists of an old masonry dam and includes the analysis of the planned rehabilitation works and their effects on the safety of the structure.

\section{Formulation of the discrete element model}

\subsection{Mechanical model}

A block with three or four edges is the fundamental discretization element used in this implementation of DEM (Bretas 2012). The blocks may be rigid or deformable, but only the latter case will be described for the sake of completeness. Each deformable block corresponds to a finite element, here assumed as a four node element with Gauss numerical integration. Blocks can be associated forming macroblocks, by slaving together coincident nodes, thus allowing any complex geometry and discretization. The blocks may also constitute a discontinuous media (Figure 1a), in which case the interaction is made through contacts. Figure $1 \mathrm{~b}$ shows the contact between the blocks 12, 1-3, 1-4, 2-3 and 2-4, designated respectively by $\mathrm{CT}_{1.2}, \mathrm{CT}_{1.3}, \mathrm{CT}_{1.4}, \mathrm{CT}_{2.3}$ and $\mathrm{CT}_{2.4}$. The contacts are of type edge-edge, with numerical implementation done through two sub-contacts (Figure $1 \mathrm{~b}$ ). The contact $\mathrm{CT}_{1.2}$ is established numerically by two subcontacts, called $\mathrm{SCT}_{1.2 .1}$ and $\mathrm{SCT}_{1.2 .2}$. Throughout the calculation, the contacts may be updated or deleted, and also new contacts can be created. The contact forces come from the relative movement of the blocks, which is checked at sub-contact level, in the 
normal and tangential directions. The contact forces are determined from a trapezoidal diagram of stress, after verification of the constitutive model. At each step, stresses in each sub-contact are updated, first by calculating predictive elastic stresses,

$$
\begin{aligned}
& \sigma=\sigma_{0}+\Delta u_{n} k_{n} \\
& \tau=\tau_{0}+\Delta u_{s} k_{s}
\end{aligned}
$$

where $\sigma$ and $\tau$ are the new normal and shear stresses; $\sigma_{0}$ and $\tau_{0}$ the normal and shear stresses in the previous step; $\Delta u_{n}$ and $\Delta u_{s}$ are the incremental normal and shear displacements; $k_{n}$ and $k_{s}$ are the normal and shear stiffness. $\sigma$ and $\tau$ are then corrected by application of the constitutive model, such as the Mohr-Coulomb model.

The equations of motion for each degree of freedom are explicitly integrated through the central difference algorithm. Deformable blocks have two degrees of freedom per node, corresponding to the translations in the horizontal and vertical directions. For the translation case, each equation of motion has the form,

$$
\begin{aligned}
& m \ddot{u}+c \dot{u}=f_{\text {TOT }} \\
& f_{\text {TOT }}=f_{E X T}+f_{I N T}+f_{C T}+f_{M}+f_{H Y D}
\end{aligned}
$$

where $\dot{u}$ is the velocity; $\ddot{u}$ is the acceleration; $c$ is the viscous damping coefficient; $m$ is the mass; $f_{\text {TOT }}$ is the total force; $f_{E X T}$ is the external force; $f_{I N T}$ is the internal force; $f_{C T}$ is the contact force; $f_{M}$ is the mass force; and $f_{H Y D}$ is the hydraulic force.

The internal forces, $f_{I N T}$, are a function of the element stress state, and are obtained by Gauss integration,

$$
f_{I N T}=\int_{A} B^{T} \sigma d A
$$

where $B^{T}$ is the strain-displacement transposed matrix; and $\sigma$ is the stress matrix.

The time step in the central difference algorithm is limited by reasons of numerical stability. To ensure a reasonable computational performance, blocks too small or materials too rigid should be avoided. The static solution is obtained by a process of dynamic relaxation (Sauvé and Metzger 1995) where, in each calculation cycle, the critical damping is applied. The critical damping is updated in each calculation cycle in accordance with the dominant dynamic behavior of the structure, estimated from the tangent stiffness and the Rayleigh quotient. For static solutions, it is not relevant to 
analyze the intermediate states of the calculation, but only the final steady state. In this case, it is possible to scale the mass of the degrees of freedom, to obtain a faster convergence.

\subsection{Hydromechanical model}

The development of the hydromechanical model is based on the assembly of a flow mesh, composed of flow channels and hydraulic nodes (Bretas 2012). The hydraulic model is superimposed on the mechanical model. The flow channel corresponds to the edge-edge contact, while the hydraulic node, associated with one or more element nodes, corresponds to a sub-contact or a set of sub-contacts around the node. The flow rates are calculated at the flow channels and the pressures are calculated at the hydraulic nodes (Figure 1c).

To determine the flow mesh, the active contacts should be first selected. After all contacts are added, hydraulic nodes are created. In terms of the flow mesh, in relation to the contact $\mathrm{CT}_{1.2}$ (Figure $1 \mathrm{~b}$ ), the flow channel overlaps the mechanical model and is designated as $\mathrm{FC}_{1}$ (Figure 1c), to determine the flow rate $\mathrm{q}_{1}$. At the ends of the flow channel $\mathrm{FC}_{1}$, pressures are installed in the hydraulic nodes $\mathrm{HN}_{1}$ and $\mathrm{HN}_{2}$, respectively $\mathrm{P}_{1}$ and $\mathrm{P}_{2}$. The hydraulic node $\mathrm{HN}_{1}$ is composed by the sub-contacts $\mathrm{SCT}_{1.3 .1}, \mathrm{SCT}_{2.3 .2}$ and $\mathrm{SCT}_{1.2 .3}$ where the flow rates $\mathrm{q}_{1}, \mathrm{q}_{2}$ and $\mathrm{q}_{3}$ converge, which will be added to determine the pressure $P_{1}$. The pressures $P_{1}$ and $P_{2}$, will act on the faces of the channel, causing a change in the hydraulic opening and hence in the permeability, which is coupled phenomenon.

\subsection{Hydromechanical calculation cycle}

The term hydromechanical suggests some degree of coupling between the mechanical interaction of the blocks, which occurs at the discontinuities, and the flow through these same discontinuities. The stress generated by the flow acting on the walls of the joints, after the balance of all acting forces, will lead to a new opening changing the conditions of permeability. Four different levels of coupling can be assumed (Figure 2), (i) Level 0, corresponds to uncoupling, in which the hydraulic opening is constant and the fluid does not act mechanically on the discontinuities, (ii) Level 1 - hydraulic opening varies according to the mechanical opening and the fluid pressure does not act on the discontinuities, (iii) Level 2 - hydraulic opening is constant and fluid acts mechanically on the discontinuities, and (iv) Level 3 - hydraulic opening varies according to the mechanical opening and the fluid acts on the discontinuities.

Figure 3 shows briefly the hydromechanical calculation cycle, for steady-state analysis. In the general case, the hydraulic calculation is carried out simultaneously with the mechanical calculation, but it may be separated. Here, the labels $1 \mathrm{~m}$ and $2 \mathrm{~m}$ represent the mechanical cycle, while the labels $1 \mathrm{~h}, 2 \mathrm{~h}$ and $3 \mathrm{~h}$ correspond to the hydraulic cycle. Label $1 \mathrm{~h}$ refers to the flow rate calculation in the various flow channels. For each flow 
channel, this process begins with the determination of the hydraulic opening. This parameter defines the permeability of the channel and plays an important role in the determination of the total flow rate.

The material to model may be relatively homogeneous, or the jointing may be random, meaning that an equivalent continuum assumption is acceptable and the hydraulic opening is chosen to represent the average permeability. The definition of the numerical hydraulic opening $\left(a_{h}\right)$ requires three reference values: a lower limit, referred as residual opening ( $a_{\text {res }}$ ), which is the minimum permeability that exists even when the joints are highly compressed; an upper limit, designated as maximum opening ( $a_{\max }$ ), a value that cannot be exceeded for numerical stability reasons, and finally, the nominal hydraulic opening $\left(a_{0}\right)$, which reflects the flow in an initial normal stress state. To implement the hydromechanical coupling, these three parameters are related with the mechanical opening, $u_{n}$ by the following equation,

$a_{\text {res }}<a_{h}=a_{0}+u_{n}<a_{\max }$

Figure 4 shows a graphical representation of equation (6). As mentioned, the hydraulic opening has a lower and an upper limit. Between these two limits, the hydraulic opening varies according to the mechanical opening. If the initial stress is null, the hydraulic opening will be smaller than the characteristic opening when the discontinuity is in compression and the mechanical opening is negative. Similarly, the hydraulic opening will be larger than the characteristic opening when the discontinuity is in tension and the mechanical opening is positive. From Figure 4 it may be also concluded that the mechanical opening varies linearly with the normal stiffness $\left(k_{n}\right)$ of the joint when it is in compression, which makes this an important parameter to the hydromechanical coupling. In an uncoupled calculation, the hydraulic opening does not change and may be equal to the nominal hydraulic opening or to an earlier stage value. The determination of the hydraulic opening is made at the sub-contact level. Since the flow is determined at the channel, it is still necessary to define a channel hydraulic opening from the openings at the two sub-contacts located at the ends,

$a_{h}=\frac{a_{h, 1}+a_{h, 2}}{2}$

where $a_{h, i}$ is the hydraulic opening of the sub-contact $i$.

The flow rate is calculated at the channel hydraulic opening. Considering a laminar flow model between two plates (Bear 1988), the flow rate is given by the "cubic flow law", as 
$Q=\frac{1}{12 \mu} a_{h}^{3} \frac{\Delta h}{L}$

$\Delta h=\left|h_{1}-h_{2}\right|$

$h_{i}=P_{i}+y_{i} \rho_{w} g$

where $\mu$ is the dynamic viscosity of the fluid; $\Delta h$ is the head difference; $L$ is the length of the discontinuity; $h_{i}$ is the head of the hydraulic node $i ; P_{i}$ is the pressure of the node $i$; $y_{i}$ is the y-coordinate of the node $i$; $\rho_{w}$ is the fluid density; and $g$ is the acceleration of gravity.

The determination of the flow rate depends on the available energy established by the hydraulic gradient, in accordance with the permeability of the media. The first influence factor is associated with the fluid properties, determined from the dynamic viscosity. The second influence factor refers to the permeability associated with the physical features of the discontinuity, defined by the hydraulic opening. Louis (1969), by means of laboratory tests, measured the energy loss along the flow in discontinuities, for different flow rates and materials with different roughness. Based on these data, the validation of the "cubic law of flow" for laminar flow in discontinuities, formed by parallel planes with low roughness, was established. Witherspoon (1980), by testing samples of granite, basalt and marble, confirmed the validation of the "cubic law of flow" for cracks in compression. In these cases, the occurrence of physical contact between the edges of the discontinuity did not prevent the existence of residual hydraulic opening.

According to Figure 3, in the next step, labeled 2h, new pressures at the hydraulic nodes are determined. For each hydraulic node, a balance of the positive and negative flow rates is computed from the sub-contacts, as,

$Q_{H N}=\sum q_{s c t}$

where $Q_{H N}$ is the sum of the input and output of flow in the hydraulic node; and $q_{s c t}$ is the flow contribution from a convergent flow channel. The pressure variation in the current calculation cycle depends on the net flow and, for compressible fluids, is given by,

$\Delta P=\frac{K_{w}}{V}\left(Q_{H N} \Delta t+\Delta V\right)$ 
where $K_{w}$ is the bulk modulus of the fluid; $\Delta P$ is the differential pressure; $\Delta V$ is the volume variation between two consecutive cycles; $V$ is the volume of the flow channel; and $\Delta t$ is the time step.

For the steady flow analysis, the volume change between two consecutive cycles does not need to be considered. Only the final pressure after the convergence of the model to an equilibrium state is relevant and this equation takes the form,

$$
P=P_{0}+K_{w} \frac{Q_{H N} \Delta t}{V}
$$

where $P$ is the pressure in the current time step; and $P_{0}$ is the pressure in the preceding time step.

Finally, all hydraulic sub-contacts associated with the node under consideration are given the same pressure, which is used to define the hydraulic forces, label 3h (Figure 3). Based on a contact edge-edge, with two sub-contacts $\mathrm{SCT}_{1}$ and $\mathrm{SCT}_{2}$ in which are installed the pressures $\mathrm{P}_{1}$ and $\mathrm{P}_{2}$, respectively, the pressures form a trapezoidal diagram acting on the face of the blocks, in the normal direction, in conjunction with existing contact forces (Figure 5). The hydraulic forces are determined by integrating the pressure diagram, according to,

$$
\begin{aligned}
& f_{H Y D, 1}=\left(P_{1}+\frac{P_{2}}{2}\right) \frac{L}{3} \\
& f_{H Y D, 2}=\left(\frac{P_{1}}{2}+P_{2}\right) \frac{L}{3}
\end{aligned}
$$

where $f_{H Y D, 1}$ is the hydraulic force to node 1 ; and $f_{H Y D, 2}$ is the hydraulic force to node 2.

In addition to the confined flow case, this formulation allows the flow analysis of the free surface condition. It is necessary to take additional precautions to avoid negative numerical pressures that may arise. Any negative pressure, obtained from equation (13), should be zeroed. It is also necessary to progressively reduce the rate of flow towards a zero pressure node in order to obtain convergence to a balanced equilibrium solution. Generally, if $h_{1}>h_{2}$ and $y_{1}>y_{2}$, but $P_{1}<\left(y_{1}-y_{2}\right) \rho_{w} g$, then the flow rate should be reduced by a factor to provide a numerically smooth representation of the free-surface condition, by simulating a gradual evolution to an unsaturated condition, 
$f_{\text {red }}=\frac{P_{1}}{\left(y_{1}-y_{2}\right) \rho_{w} g}$

\subsection{Numerical stability}

Similarly to what occurs in the mechanical calculation, the hydraulic time step needs to be limited to achieve numerical stability of the explicit algorithm. The hydraulic time step for a given hydraulic node is directly proportional to its volume and inversely proportional to the conductivity of the flow channels connected to it, and is given by,

$$
\begin{aligned}
& \Delta t_{h}=\min \left(\frac{\sum V_{i}}{K_{w} \sum k_{i}}\right) \\
& k_{i}=\frac{1}{12 \mu} a_{h, i}^{3} \frac{1}{L_{i}}
\end{aligned}
$$

where $\Delta t_{h}$ is the hydraulic time step; $V_{i}$ is the volume of the flow channel $i ; k_{i}$ is the conductivity of the flow channel $i$; and $L_{i}$ is the length of the flow channel $i$.

Equation (17) refers to a given hydraulic node and the summation on the index $i$ extends to all the contacts (hydraulic channels) that converge towards this node. For steady state flow analyses, volumes can be scaled to obtain a given time step,

$$
V_{s}=\Delta t_{\min } K_{w} \sum k_{i}
$$

where $V_{s}$ is the scaled volume of the flow channel; and $\Delta t_{\min }$ is the minimum time step of all hydraulic nodes in the system.

It is possible to scale the volume with the bulk modulus of the fluid, thus eliminating the definition of this parameter. However, it is more intuitive to maintain the initial formulation, since the bulk modulus is physically meaningful. In steady state hydromechanical analysis, hydraulic calculations are carried out simultaneously with the mechanical calculation. In this case, it is convenient to adopt a common time step, so that the volumes should be scaled with relation to the minimum time step, either the mechanical or the hydraulic time step. For true transient analysis, different time scales must be used.

\subsection{Analysis of flow with Bingham fluid}


The grout used for the treatment and consolidation of dams and foundations has a rheological behavior of a Bingham fluid, while the water is a Newtonian fluid. Bingham fluids present a viscous-plastic behavior, characterized by cohesion and viscosity, with flow only taking place if the hydraulic gradient exceeds a threshold value which is a function of the cohesion and the joint opening, Lombardi (1985). This formulation is implemented in the present numerical model to simulate grout injection processes (Bretas 2012).

\subsection{Boundary conditions and other restraints}

Hydraulic boundary conditions and other restraints must be adequately modeled. The lateral and the base boundaries of the foundation are generally considered impermeable. On the foundation surface upstream of the dam, a fixed pressure is applied, equivalent to the level of the reservoir. Similarly for the foundation surface downstream the dam the tailwater level is considered. On the upstream and downstream faces of the dam, triangular or trapezoidal pressure diagrams are applied. Free surface flow takes place inside the masonry dam, which usually features high permeability. Therefore, the top face of the crest and the downstream face of the dam are assigned a permeable boundary condition.

Another important aspect is the ability to model drainage systems and grout curtains. A drainage system is represented by fixing the hydraulic pressure in the nodes located in the alignment of the drains, varying in depth according to the hydrostatic gradient. The pressure at the top of the drains may be set to zero, or to the typical values prescribed in the design codes. It is also possible to impose the discharge flowing out of the drains. In this case, the pressures will be obtained from the flow analysis. To model the grout curtain, the conductivity of the hydraulic channels within the grouted region is reduced. The grout curtain is a particular case of local permeability change, but may be applied to wider areas. For example, the rock mass usually does not have a uniform permeability, being higher closer to the surface.

The final aspect to mention regarding the hydromechanical modeling of masonry gravity dams arises in earthquake analysis. During an earthquake, for existing cracks filled with water, the water pressure may be assumed to remain constant. In practice the flow calculation is interrupted and the hydraulic pressures already installed remain unchanged. Alternatively, transient water pressures may be considered, even if the flow is turned off. However, the dynamic effects of water inside the body of the dam may be modeled by means of additional masses applied to the degrees of freedom that are saturated. The determination of these additional masses depends on the porosity and on the mass assigned to the degree of freedom, as,

$$
m_{a d, i}=m_{i} \eta \frac{\rho_{w}}{\rho_{b}}
$$


where $m_{a d, i}$ is the additional mass distributed to node $i$; $m_{i}$ is the mass of node $i$; $\eta$ is the porosity; and $\rho_{b}$ is the density of the dam material. The criterion to define the region of the dam which is saturated should be based on the value of the hydraulic pressure that exceeds a specified value, e.g. $5 \%$ of the maximum pressure.

The required properties of the fluid are the bulk modulus, the density and the kinematic or dynamic viscosity. It should be noted that the density and viscosity vary with temperature, with lower values as the temperature increases. In the reservoir, the temperature decreases in depth until becoming constant, both in summer and winter, standing at about $4^{\circ} \mathrm{C}$. For high dams, the properties may be calculated for $4^{\circ} \mathrm{C}$. For low dams, a $20^{\circ} \mathrm{C}$ reference temperature may be used. This criterion is adopted in the application case presented herein. Thus, the bulk modulus of water is equal to $2.0 \mathrm{GPa}$, density is equal to $1000.0 \mathrm{~kg} / \mathrm{m}^{3}$ and kinematic viscosity is equal to $10^{-6} \mathrm{~m}^{2} / \mathrm{s}$.

\section{Case study}

\subsection{Description of the dam and the rehabilitation works}

Póvoa Dam (Figure 6a) is located near the towns of Póvoa and Meadas, in Portalegre district, in southern Portugal. It is a masonry gravity dam, built between 1925 and 1928, whose hydroelectric central is deployed in the valley, about $140 \mathrm{~m}$ downstream of the dam. The complete dam consists of four structures: the main dam, with a maximum height of $28.5 \mathrm{~m}$ and a length of $220 \mathrm{~m}$, with a small curvature; a secondary body with a maximum height of $13.5 \mathrm{~m}$ and a length of $155 \mathrm{~m}$, a transition on the right bank; a smaller body, with a maximum height of $5 \mathrm{~m}$ and a length of $45 \mathrm{~m}$, springing also on the right bank; and an uncontrolled spillway, located on the left bank, without connection with the remaining structure, with a maximum height of $3 \mathrm{~m}$ and a length of $120 \mathrm{~m}$. The maximum discharge capacity comprises the principal spillway with of 80

$\mathrm{m}^{3} / \mathrm{s}$, a flood discharge with a capacity of $8 \mathrm{~m}^{3} / \mathrm{s}$ and the bottom outlet with a capacity of $4 \mathrm{~m}^{3} / \mathrm{s}$.

Figure $6 \mathrm{~b}$ represents the central section of the main dam. A high volume of infiltrated water has been observed on the dam-foundation surface, about $300 \mathrm{l} / \mathrm{min}$ for a reservoir level of $24 \mathrm{~m}$ (with respect to the foundation). For higher reservoir levels, the infiltrated water increases substantially, reaching about $1400 \mathrm{l} / \mathrm{min}$ (reservoir level of $27.2 \mathrm{~m}$ ). There is also a high groundwater level within the dam, reaching above $40 \%$ of the upstream water level. The chemical analyses of drained water show low dissolution of calcium carbonate, which indicates that most of the calcium constituents were already leached (LNEC 2011). The rehabilitation project includes the execution of a grouting curtain, from the dam crest, to decrease the permeability and improve the consolidation of the dam, which extends through the foundation. Other interventions are planned for 
the hydraulic systems, such as the redesign of the flood spillway, of the bottom outlet and of the water intake as well as of the drainage system.

A series of analyses to assess the current structural safety conditions of Póvoa Dam and evaluate the expected behavior after the rehabilitation works were carried out. The material properties for the dam are described in Table 1, for both conditions, before and after the rehabilitation. For the foundation material, rehabilitation is not expected to alter the properties of the material, except locally, as discussed next. The stiffness of the dam-foundation interface was assumed equivalent to 1 meter of dam material. Therefore, the normal stiffness is $5 \mathrm{GPa} / \mathrm{m}$, while the tangential stiffness is $1.5 \mathrm{GPa} / \mathrm{m}$. The dam was built on a competent granite foundation, presenting a porphyroid texture with gross to very gross grains, and two micas (biotite and muscovite). The rock mass is slightly weathered and fractured except below the secondary dam, as described above, where weathering is much more evident.

After the rehabilitation, an increase of the dam material density is expected because the grout to be injected will partially fill the voids existing in the masonry. As result of this consolidation, doubling of the elasticity modulus is estimated. The permeability values, measured as current condition before rehabilitation, are given in Figure 7a. The permeability of the foundation does not change with the rehabilitation, except locally, as the grouting curtain will be extended by the foundation to a depth of $10 \mathrm{~m}$ (Figure 7b). All materials properties are based on the rehabilitation design (EDP 1994). An extensive set of field and laboratory tests was carried out. A total of $227 \mathrm{~m}$ of boring was drilled, distributed by 12 holes, from the crest of the dam through the foundation. Laboratory tests were undertaken to characterize the physical and mechanical properties of the material. Field tests took place to assess the permeability and injectability of the media.

The grouting curtain, within the dam, will be composed of a main zone with a very low permeability, estimated to be near to $10^{-7} \mathrm{~m} / \mathrm{s}$, and a secondary zone, characterized by transition band, where a permeability of about $10^{-6} \mathrm{~m} / \mathrm{s}$ is expected (Figure $7 \mathrm{~b}$ ). For the drainage system, for each $4.5 \mathrm{~m}$ of linear development of the dam, five drains will be installed (Figure 7b): two drains inside the dam body, upper dam drain (UDD) and lower dam drain (LDD), with the uppermost end, in both cases, located on the downstream face; and three drains in the foundation, two of them with the upper end located in the drainage gallery, designated as shallow foundation drain (SFD) and deep foundation drain (DFD), and finally the downstream drain (DD) with the upper end on the downstream face, near the downstream toe. To model the drains, pressures were determined based on the elevation of the upper end of each drain, where zero pressure is prescribed, with a hydrostatic distribution along the drain, defined at the points that coincide with the hydraulic nodes, according to the mesh discretization (Figure 8). This assumption assumes the effectiveness of the drainage system, which should be observed during the full lifecycle of the dam.

In this example, as the only permeability data refers to average values for each zone, a simplified block pattern was adopted, with the joint openings calibrated to provide the 
required permeability. This model allows the representation of the main failure mechanism to be assessed, which involves sliding of the dam-rock interface.

\subsection{Uplift diagrams on the dam foundation and equipotential line contours in the dam-foundation system}

Figure 9a provides uplift diagrams for several modeling assumptions before rehabilitation, including the (i) traditional linear diagram, (ii) the uncoupled model, (iii) the coupled model considering the dam as an impervious media and (iv) the fully coupled model. The values of uplift forces, per unit out of plane dimension, obtained by the integration of these diagrams are shown in Table 2 . The values relative to the selfweight of the dam, are shown before $(7941 \mathrm{kN} / \mathrm{m})$ and after rehabilitation $(8106 \mathrm{kN} / \mathrm{m})$. The relative values of uplift, are $40 \%$ of the dam self-weight for the theoretical case, $45 \%$ for the uncoupled model, $49 \%$ for coupled case with the dam impervious and $52 \%$ for the coupled full model. This uncoupled numerical model considers the dam as a permeable medium, leading to pressures slightly higher than the classical linear diagram, as a consequence of the inflow from the dam upstream face. Coupling increases the uplift pressures as the permeability in the compressed downstream area becomes lower than in the uncoupled model. The results indicate that is important to adopt hydromechanical coupled models and, in the cases where the dam is highly permeable, the flow should be evaluated through its body together with the foundation.

After the rehabilitation Figure 9b, taking account the effect of the grout curtain, the uplift represents about $40 \%$ of the dam self-weight. In this example, the reduction provided by the grouting curtain is not significant because the curtain is relatively short and the gradient imposed is small, being its main role to reduce the flow rate. The solution with the drainage system reduces the value of the uplift to about $24 \%$ of the dam self-weight. The action of the grout curtain in conjunction with the drainage system reduces the uplift to this last value. In both cases, the action of the drainage system is preponderant.

Figure 10 provides respectively the variation of the hydraulic head in the hydromechanical coupled flow analysis, before and after rehabilitation works, with grout curtain and drainage. In the first case, Figure 10a, the coupling effect is relatively small in the foundation and the equipotential contours are distributed uniformly in this zone. There is also flow through the dam body, from the upstream towards the downstream face, which develops perpendicularly to the equipotential lines. In Figure $10 \mathrm{~b}$ the influence of the grouting curtain and drainage system is visible in the variation of the contours, namely in the areas where the equipotential curves are very close. The action of the drainage system modifies drastically the flow conditions, for example in case of deep foundation drain (DFD) which introduces a discontinuity in the hydraulic potential. 


\subsection{Flow rate drained through the dam, the foundation and the drainage system}

The hydraulic boundaries where the reservoir head is prescribed are the bottom of the reservoir and the upstream face of the dam. The water can leave through the surface of the foundation, on the downstream face of the dam, and through the drainage system. Table 3 shows the values of total discharges. The grouting curtain decreases the total flow rate, while the drainage system increases it, as expected. It also appears that, due to the high permeability of the dam, the water percolates mainly through its body. This behavior changes in presence of the drainage system, which collects much of the flow that seeps through the dam and foundation. From the analysis of these results, the complementary role of the grout curtain and drainage system is confirmed, reducing the uplift as well the total flow rate. The distribution of the water volume through the drainage system was analyzed (Figure 11). The drains with greater volume were the UDD (upper dam drain) and the SFD (shallow foundation drain).

Two additional analyses were performed: (i) analysis of flow rate distribution in the drainage system with only four drains, excluding the drain LDD and (ii) analysis of flow rate distribution in the drainage system with only four drains, excluding the drain DD. In the original analysis, both drains, LDD and DD, had a very low drained volume of water. In the first case, the uplift remained practically the same. The flow rate, previously drained through LDD, was equally distributed between the SFD and UDD. The LDD does not seem to have a significant role in the reduction of pressure or in the improvement of the structure safety. In case of excluding DD the uplift is increased 4\% and the flow rate, before drained by DD, now goes through the downstream face. This new flow condition could cause a progressive degradation of the material near the toe of the dam and it seems appropriate to maintain the drain DD.

\subsection{Analysis of the sliding scenario of the dam through the foundation}

A parametric analysis of the friction angle was undertaken to evaluate the sliding scenario through the interface between the dam and the foundation. The loads include the self-weight of the dam, the hydrostatic pressure in the upstream face adjusted to the reservoir level equivalent to the crest elevation, and the uplift given by the flow analysis. For the dam-foundation contact, a non-linear model with no tension criteria and zero cohesion was assumed. The friction angle was gradually reduced, until an unstable situation developed.

The sliding safety factor (SF), determined for a reference angle of $45^{\circ}$, is significantly affected by the uplift forces. For the model with the initial conditions, before rehabilitation, the SF is equal to 1.0. After the rehabilitation of the dam and foundation, with curtain and drainage, the $\mathrm{SF}$ is equal to 1.5 , considered sufficient in most regulatory codes. 
Figure 12 shows the stress diagrams for the case after rehabilitation. For a friction angle of $55^{\circ}$ (Figure 12a) only the initial $5 \mathrm{~m}$ fail in shear, where the shear stress diagram is coincident with the shear stress limit. As expected, for a friction angle of $45^{\circ}$ (Figure $12 \mathrm{~b}$ ), the shear stress limit diagram is coincident with the effective vertical stress because the friction coefficient is equal to 1.0. For $35^{\circ}$ (Figure 12c) shear failure is extending from upstream and downstream. In the last case, friction angle of $30^{\circ}$ (Figure 12d), all the dam-foundation surface is at slip condition.

\section{Conclusions}

The hydromechanical model developed in this paper fulfils the objective of having an adequate tool for the analysis of masonry gravity dams, allowing an effective integration of static and flow analyses. This integration is enhanced by the consistency of the hydraulic and mechanical data models. The hydromechanical model allows the analysis of concrete or masonry gravity dams with grout and drainage systems. Drains are represented by sets of hydraulic nodes along their alignment. The grout curtain is represented by changing the properties of the hydraulic channels that connect the nodes.

For masonry dams, it is important to analyze the dam body and rock foundation in an integrated manner. The case study presented showed the importance of considering the flow through the dam body, especially in the case of old deteriorated dams. The results also confirm that coupling of grouting and drainage provides satisfactory solutions that reduce the uplift and flow rate simultaneously. In the case studied, sliding on the damrock interface was the major safety concern, but the discrete element model is also capable of analyzing failure modes through the dam body or the rock foundation, for cases with more complex discontinuity patterns.

\section{Acknowledgement}

Permission by EDP to present the example data is gratefully acknowledged. The first author also acknowledges the financial support of the Portuguese Science Foundation (Fundação de Ciência e Tecnologia, FCT), through grant SFRH/BD/43585/2008. 


\section{References}

Barla G., Bonini M., Cammarata G. 2004. Stress and seepage analyses for a gravity dam on a jointed granitic rock mass. Proc. of the 1st Int. UDEC/3DEC Symposium: Numerical Modeling of Discrete Materials in Geotechnical Engineering, Civil Engineering, and Earth Sciences, Bochum, pp. 263-268.

Bear, J. 1988. Dynamics of fluids in porous media. Dover Publications, Inc., New York.

Bettzieche, V., Deutch, R., Heitfuss, C. 2004. 100 years of experience in ageing of masonry aams and life-time-based rehabilitation. 2nd International Conference on Lifetime Oriented Design Concept - ICOLD 2004, Bochum.

Bretas, E.M., Lemos, J.V., Lourenço, P.B. 2012. Masonry dams: Analysis of the historical profiles of Sazilly, Delocre and Rankine, International Journal of Architectural Heritage, 6(1):19-45.

Bretas, E.M. 2012. Development of a discrete element model for masonry gravity dams analysis (in Portuguese). Ph.D. Thesis. Engineering School. University of Minho. Available from www.civil.uminho.pt/masonry.

Cammarata, G., Fidelibus, C., Cravero, M., Barla, G. 2004. The hydro-mechanically coupled response of rock fractures, Rock Mechanics and Rock Engineering, 40(1): pp. 41-61.

Casagrande, A. 1961. First Rankine Lecture: Control of seepage through foundations and abutments of dams. Géotechnique, XI(3): 161-182.

Char, S.A., Mital, B.K., Chakrabarty, N.C. 1991. Seepage control through masonry dams and foundation of concrete/masonry dams. Research Needs in Dam Safety, Proceedings of the First Conference. New Delhi, VII: 1-8.

Chatterjee, K.K., Chibber, I.B., Shenoi, R.S. 1991. Chemistry of underseepage in dam safety Tons barrage, India. Research Needs in Dam Safety, Proceedings of the First Conference. New Delhi, VII: 13-18.

EDP 1994. Hydroelectric production center of Ribeira de Nisa - Póvoa Dam: Rehabilitation design (in Portuguese). EDP, Porto.

Eglinton, M.S. 1987. Concrete and its chemical behavior. Thomas Telford, London.

Erban, P.J., Gell, K. 1988. Consideration of the interaction between dam and bedrock in a coupled mechanic-hydraulic FE-program, Rock Mechanics and Rock Engineering, 21(2): pp. 99-117.

Gimenes, E., Fernández, G. 2006. Hydromechanical analysis of flow behavior in concrete gravity dam foundations. Canadian Geotechnical Journal 43: 244-259. 
ICOLD 1983. Deterioration of dams and reservoirs - Examples and their analysis. ICOLD, Paris.

Itasca 2011. Universal Distinct Element Code (UDEC) - Version 5.0, Minneapolis.

LNEC 2011. Póvoa Dam - Inspection of the structure and the monitoring system November, 2010 (in Portuguese). LNEC, Lisbon.

Lombardi, G. 1985. The role of cohesion in cement grounting of rock (Q. 58, R. 13). 15th Congress of Large Dams. ICOLD, Lausanne, pp. 235-261.

Lombardi, G.. 1992. The FES rock mass model - Part 2: Some examples. Dam Engineering, 3(3): 201-221.

Louis, C. 1969. A study of groundwater flow in jointed rock and its influence on the stability of rock masses. Ph.D. Thesis. (in Germany), Karlsruhe University, Karlsruhe. Imperial College Rock Mechanics Research, Report N. ${ }^{0} 10$ (English translation), London.

Paolina, R., Appendino, M., Baldovin, E., Berra, M., Bianchini, A., Carabelli, E., Posta, U., Vielmo, I. 1991. Deterioration problems for concrete and masonry dams in Italy. 17th ICOLD Congress on Large Dams, Vienne, Q. 65, pp. 785-815.

Rutqvist, J., Stephansson, O. 2003. The role of hydromechanical coupling in fractured rock engineering. Hydrogeology Journal 11:7 7-40.

Ruggeri, G. 2004. Uplift Pressures under concrete dams, ICOLD European Group.

Sauvé, R.G., Metzger, D.R. 1995. Advances in dynamic relaxation techniques for nonlinear finite element analysis. Journal of Pressure Vessel Technology, 117(2): 170176.

Scuero, A., Vale, J., Vaschetti, G., Quintela, A., Silva, A.R., Ramos, J.M., Costa, A.S. 2007. Rehabilitation of Covão do Ferro masonry dam. 5th International Conference on Dam Engineering, Lisbon.

Serafim, J.L. 1968. Influence of interstitial water on the behaviour of rock masses. Rock Mechanics in Engineering Practice. John Wiley \& Sons, London, pp. 55-97.

Silveira, A.F., Ramos, J.M. 1994. Strengthening and raising of Lagoa Comprida dam. 18th ICOLD Congress on Large Dams, Durban, Vol. III, Q. 70, pp. 199-210.

Soyeaux, R. 1990. Seepage flow under dams with jointed rock foundations - A discrete hydraulic model with respect to laminar and turbulent flow. Rock Joints: Proceedings of the International Symposium on Rock Joints, Loen, pp. 745-752. 
Stematiu, D. 1990. The modeling of water flow through fissure matrix and major joints of a dam foundation rock. Rock Joints: Proceedings of the International Symposium on Rock Joints, Loen, pp. 753-758.

Wei, L., Hudson, J.A. 1988. A hybrid discrete-continuum approach to model hydromechanical behaviour of jointed rocks, Engineering Geology, 49(3-4): 317-325.

Witherspoon, P.A., Wang, J.S.Y., Iwai, K., Gale, J.E. 1980. Validity of cubic law for fluid flow in deformable rock fracture, Water Resources Research, 16(6): 1016-1024.

Wittke, W., Wittke, M., Kiehl, J.R. 2012. Interaction of a masonry dam and the rock foundation, Geotech Geol Eng, Published online: 02 February 2012. 
(a) Block model

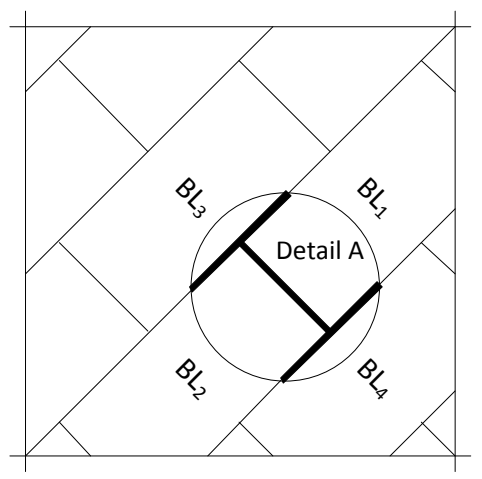

$\mathrm{Bl}_{\mathrm{i}}-$ Block $\mathrm{i}$ (b) Mechanical model

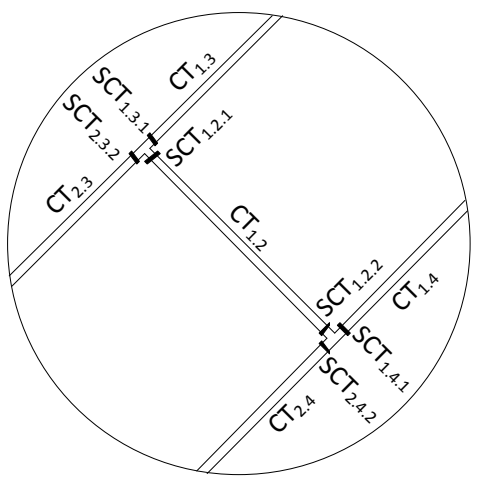

$\mathrm{CT}_{\mathrm{i}, \mathrm{j}}$ - Contact between block $\mathrm{i}$ and $\mathrm{j}$ $\mathrm{SCT}_{i, j . k}$ - Sub-contact $k$, from contact i.j (c) Hydraulic model

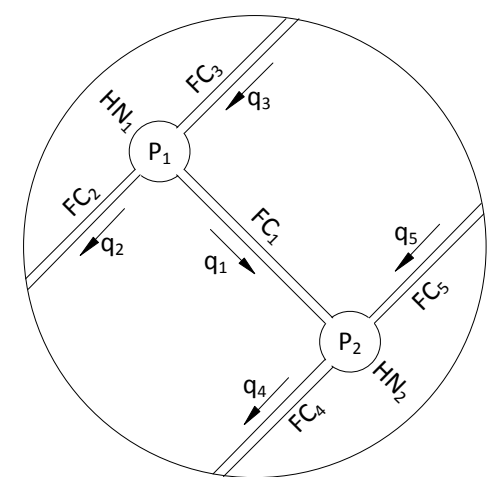

$\mathrm{HN}_{\mathrm{i}}-\mathrm{Hydraulic}$ node i $\mathrm{P}_{\mathrm{i}}$ - Pressure on $\mathrm{HN}_{\mathrm{i}}$ $\mathrm{FC}_{\mathrm{j}}$ - Flow channel $\mathrm{j}$ $\mathrm{q}_{\mathrm{j}}$ - Flow rate on $\mathrm{FC}_{\mathrm{j}}$

Figure 1 - Block model (a), mechanical model (b) and hydraulic model (c) 


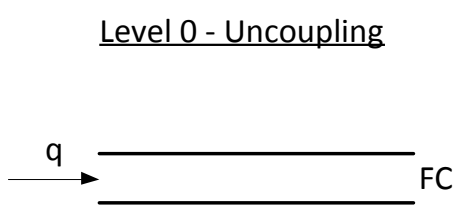

Level 2 - Coupling

Hydraulic effect

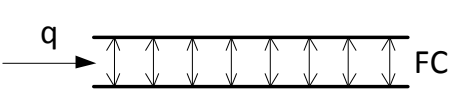

Level 1 - Coupling

Mechanical effect

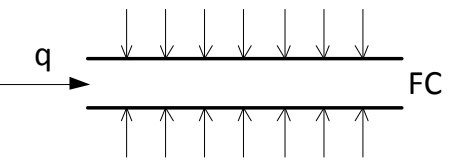

Level 3 - Coupling

Hydraulic and mechanical effect

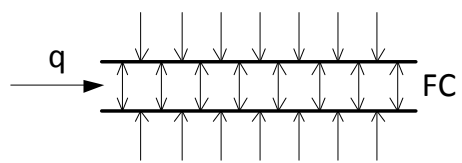

Figure 2 - Hydromechanical coupling levels 


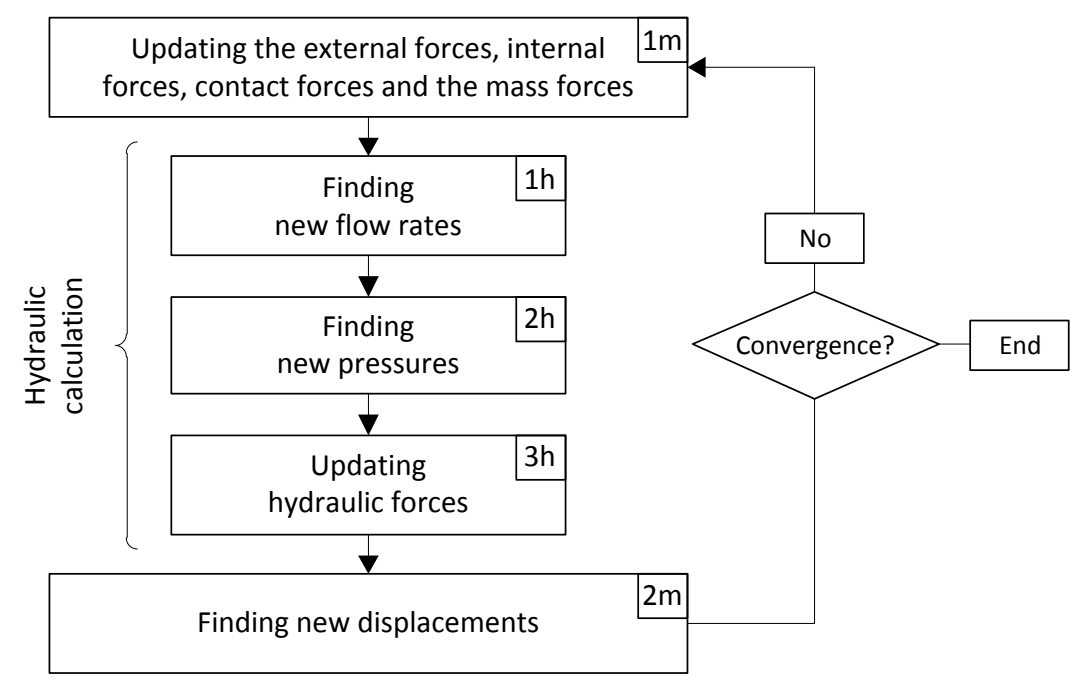

Figure 3 - Hydromechanical calculation cycle 


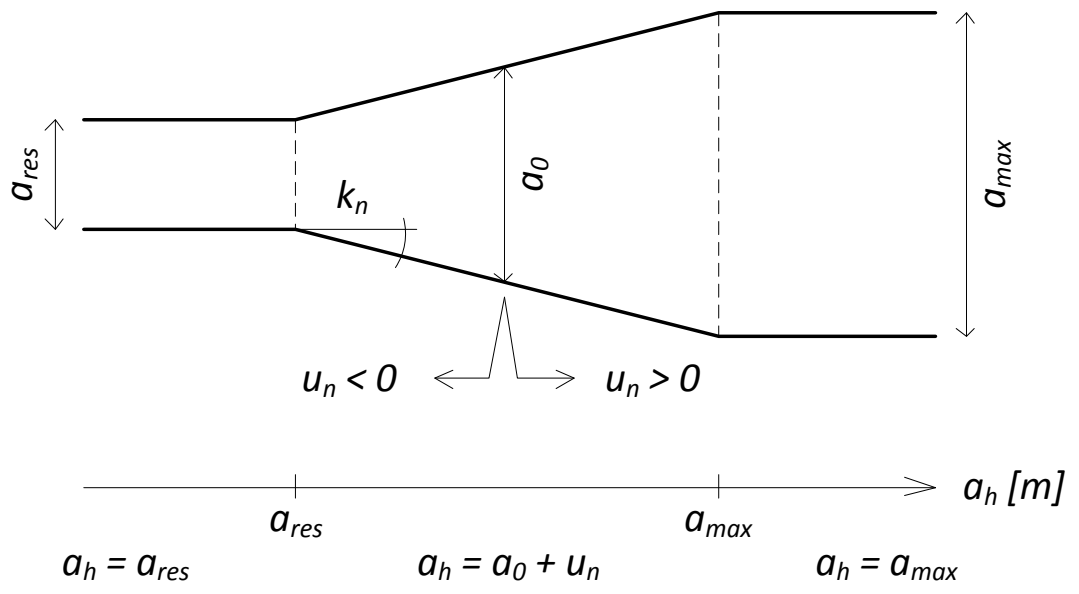

Figure 4 - Calculation scheme for the hydraulic opening 
Flow

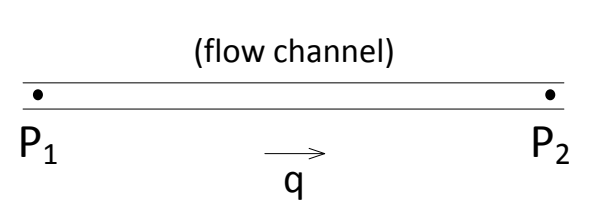

$\frac{\uparrow f_{H Y D, 1} \quad f_{H Y D, 2} \uparrow}{\dot{\downarrow} f_{H Y D, 1}}$

$\underline{\text { Hydraulic forces }}$

Figure 5 - Mechanical effect during hydromechanical analysis
Pressure diagram
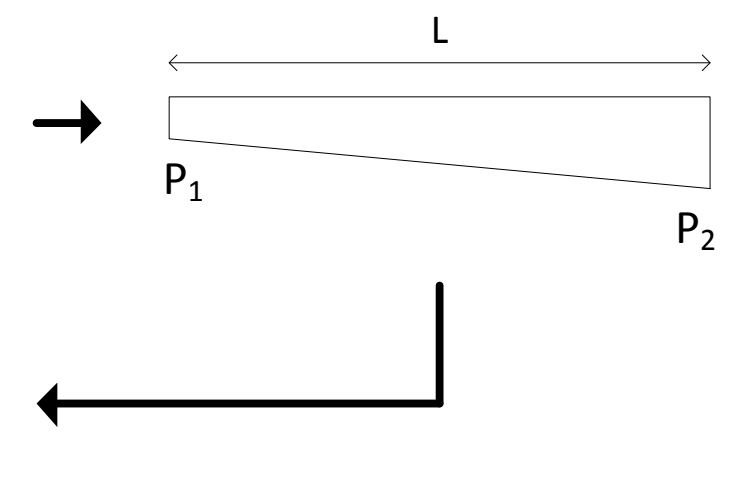


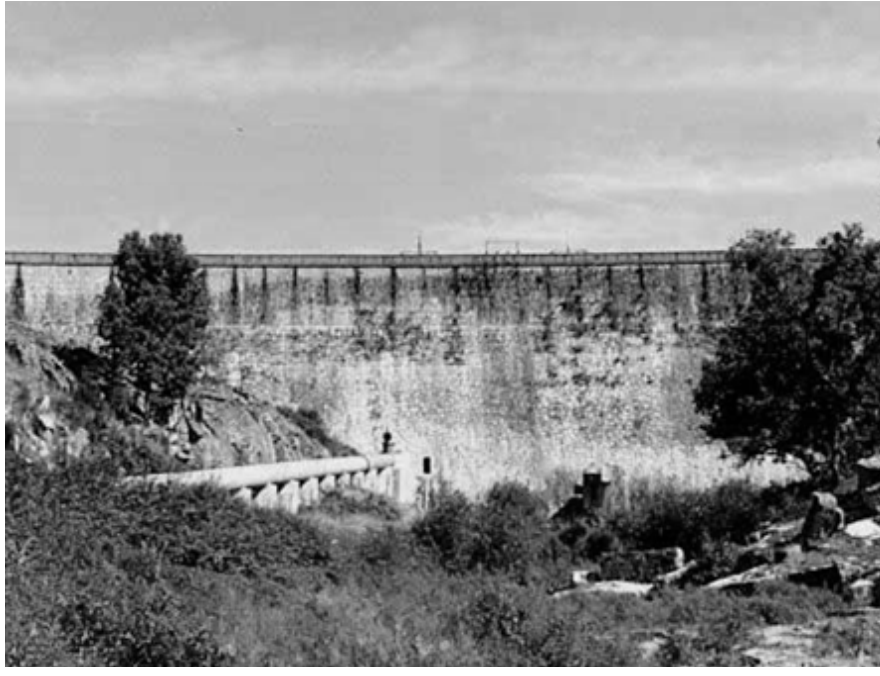

(a) View of Póvoa Dam

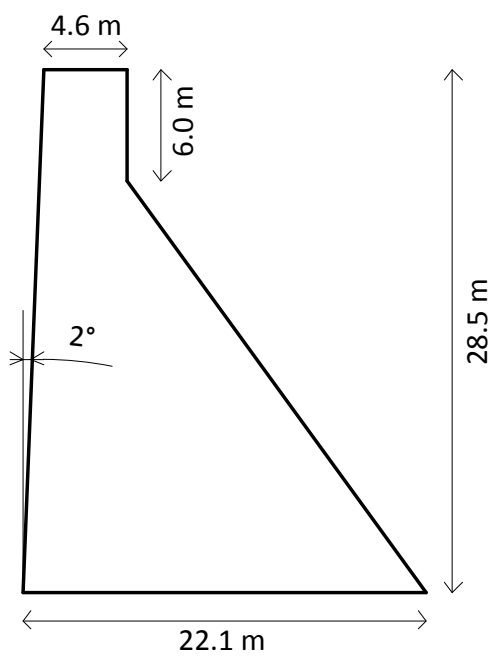

(b) Section of Póvoa Dam

Figure 6 - View (a) and section (b) of the main structure of Póvoa Dam 


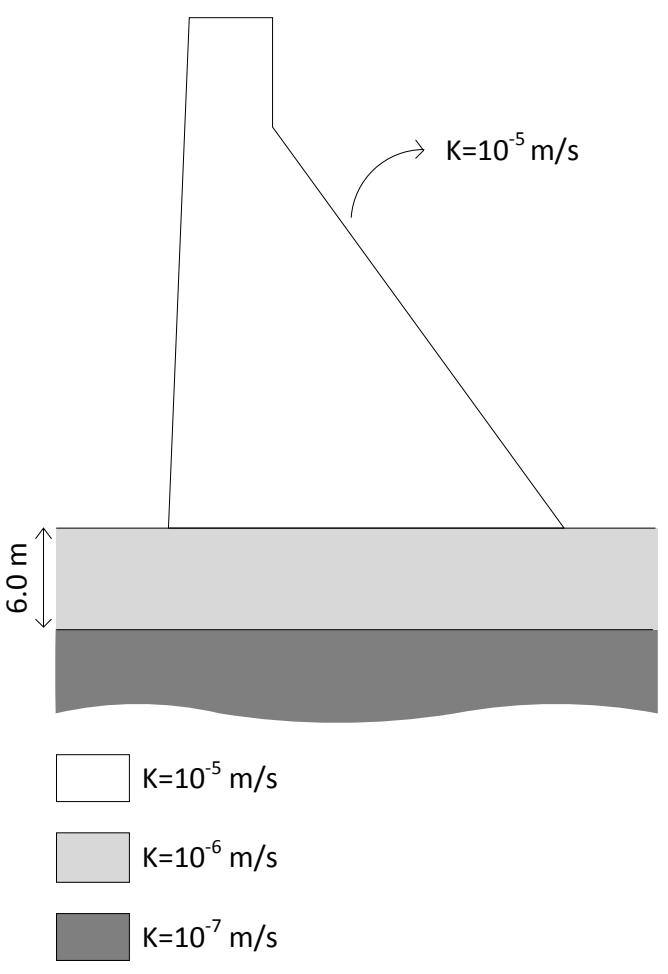

(a) Permeability properties before rehabilitation

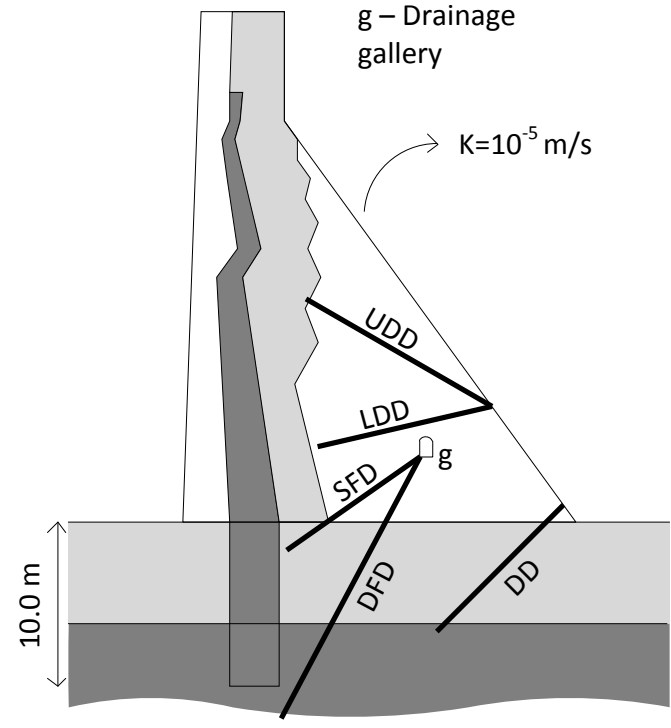

\section{Drains:}

UDD - Upper dam drain

LDD - Lower dam drain

SFD - Shallow foundation drain

DFD - Deep foundation drain

DD - Downstream drain

(b) Permeability properties and drainage system after rehabilitation

Figure 7 - Permeability properties of the model before rehabilitation (a) and after rehabilitation with the new drainage system (b) 


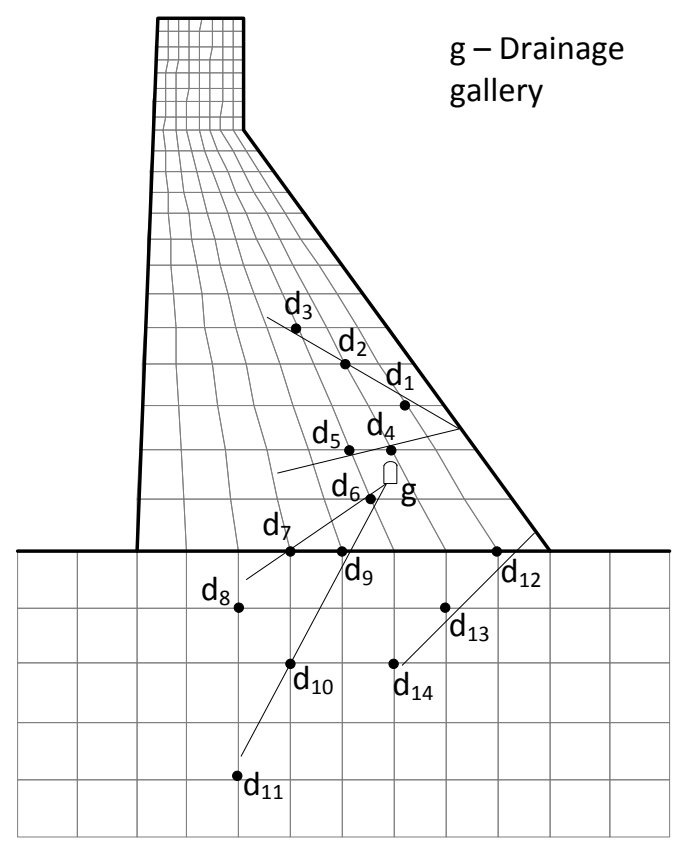

Fix pressure nodes [kPa]:

UDD: $d_{1}=0.0, d_{2}=0.0, d_{3}=0.0$

LDD: $d_{4}=11.0, d_{5}=11.0$

SFD: $d_{6}=9.0, d_{7}=37.0, d_{8}=67.0$

DFD: $d_{9}=37.0, d_{10}=97.0, d_{11}=158.0$

DD: $d_{12}=10.0, d_{13}=40.0, d_{14}=70.0$

Figure 8 - Drain system modeling according to the mesh discretization 


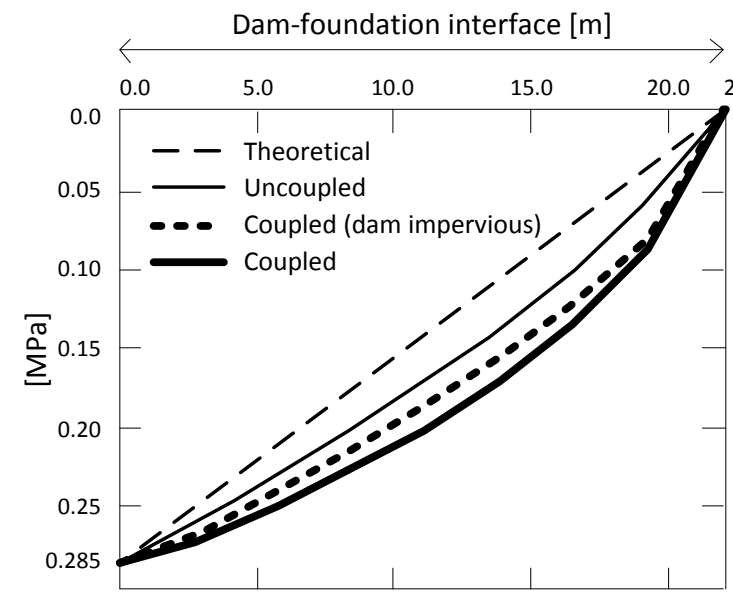

(a) Uplift diagrams for the initial conditions, before rehabilitation

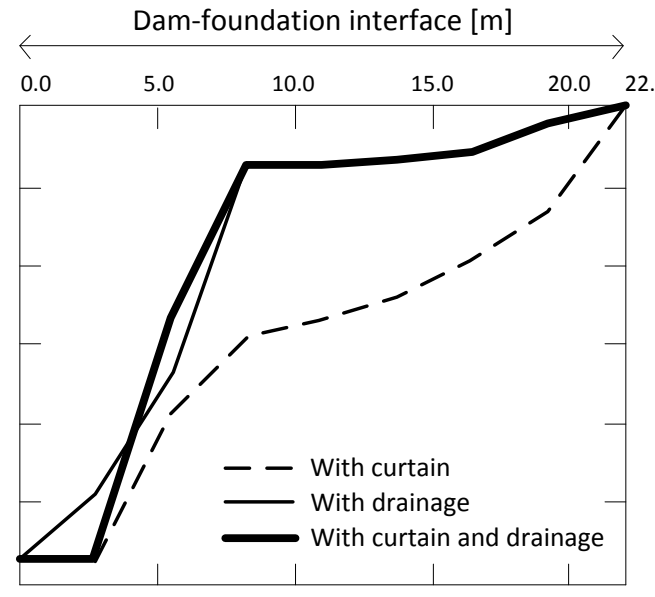

(b) Uplift diagrams for the final conditions, after rehabilitation

Figure 9 - Uplift diagrams for the initial conditions, before rehabilitation (a) and after rehabilitation (b) 


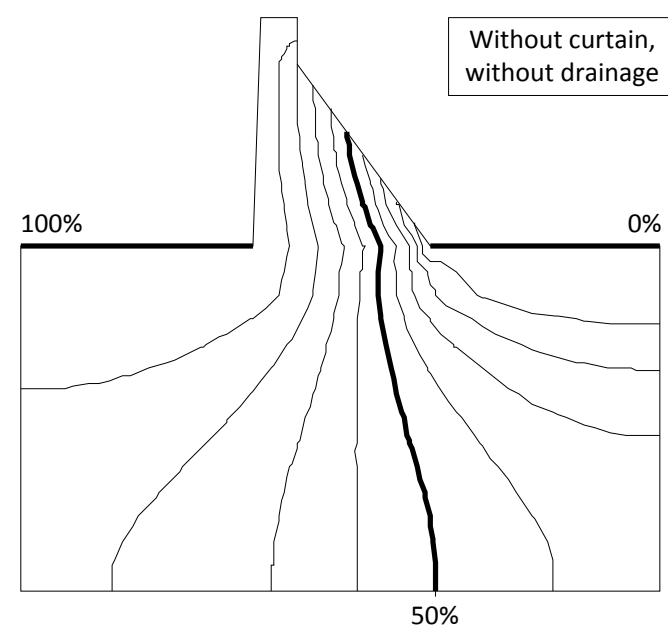

(a) Equipotential lines before rehabilitation works

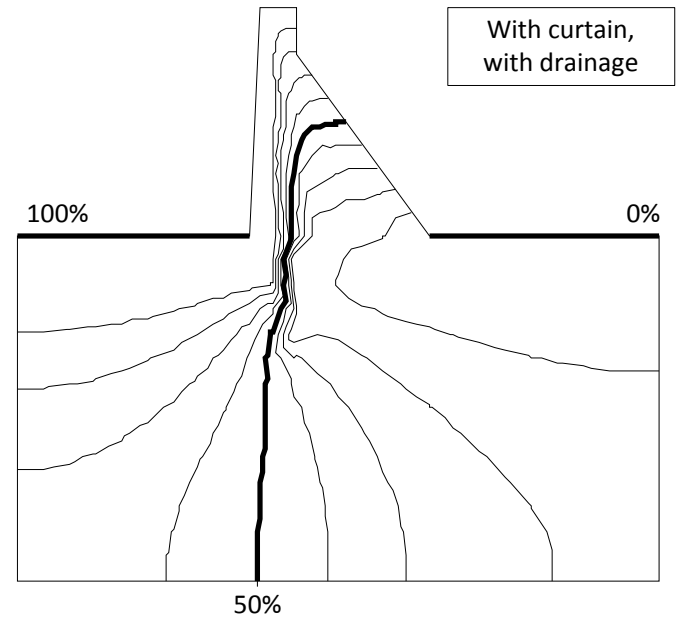

(b) Equipotential lines after rehabilitation works

Figure 10 - Equipotential lines before rehabilitation works (a) and after rehabilitation works (b) 


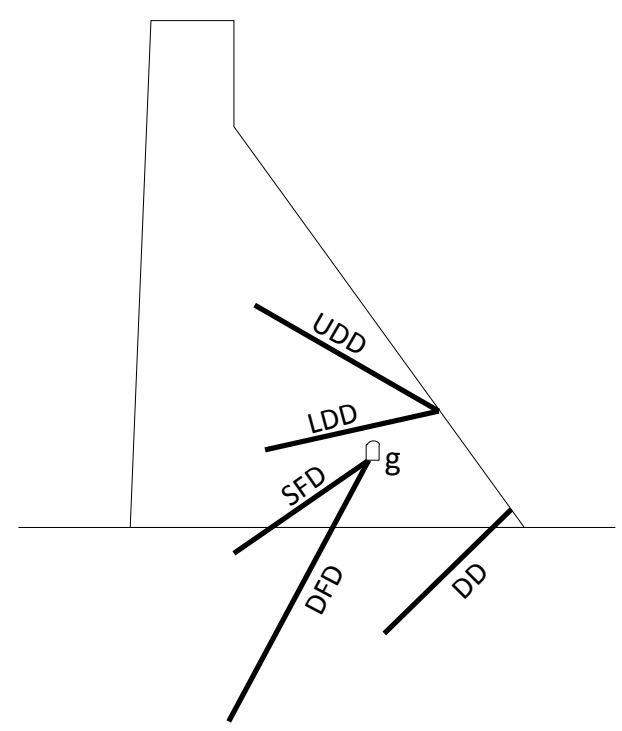

(a) Drains identification

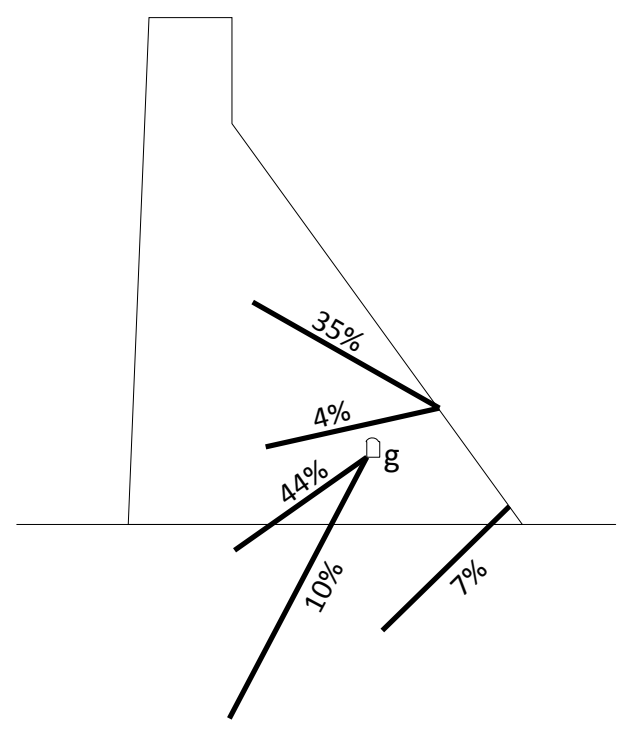

(b) Distribution of the flow rates to the drainage system

Figure 11 - Distribution of the flow rates to the drainage system 


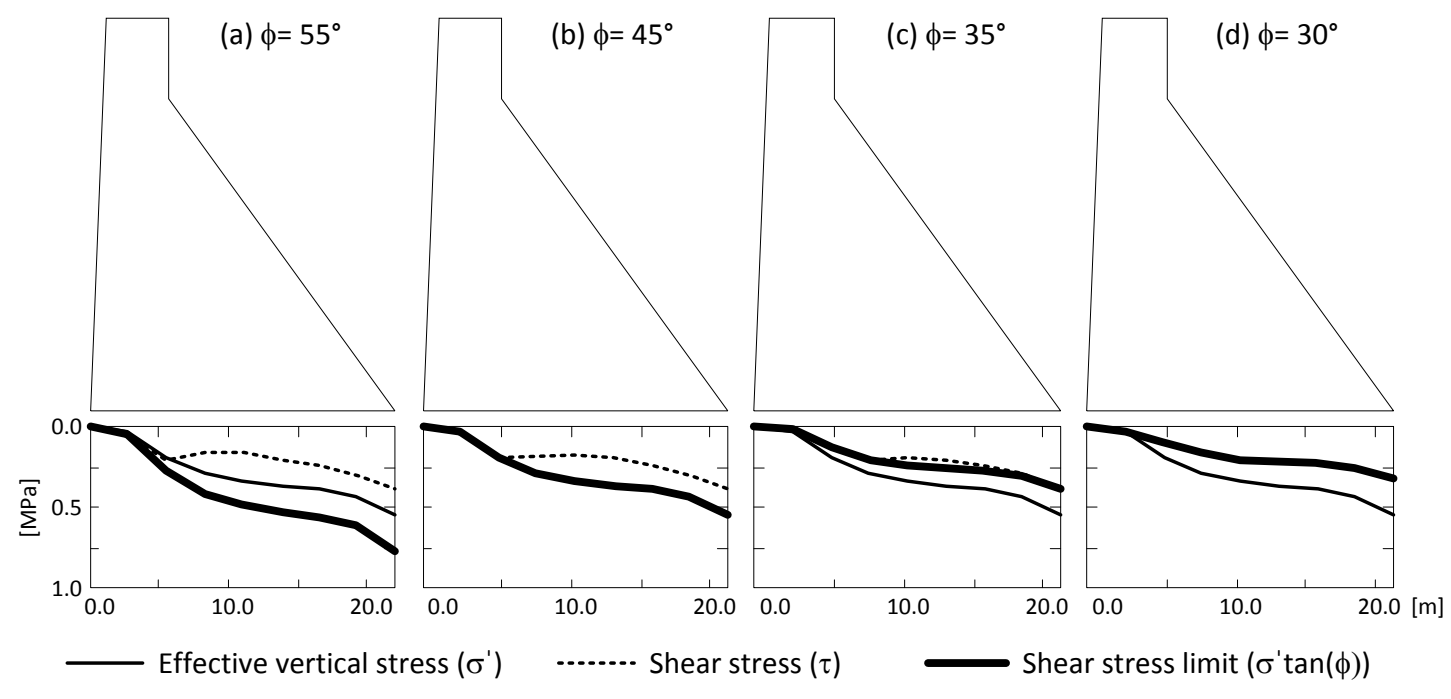

Figure 12 - Effect of the friction angle reduction on the extension of the failure for the case after rehabilitation 
Table 1 - Properties of the materials

\begin{tabular}{|c|c|c|c|}
\hline \multirow{2}{*}{ Property } & \multicolumn{2}{|c|}{ Dam } & \multirow{2}{*}{$\begin{array}{c}\text { Foundation } \\
\text { (Before and after } \\
\text { rehabilitation) }\end{array}$} \\
\hline & $\begin{array}{c}\text { Before } \\
\text { rehabilitation }\end{array}$ & $\begin{array}{c}\text { After } \\
\text { rehabilitation }\end{array}$ & \\
\hline Density $\left[\mathrm{kg} / \mathrm{m}^{3}\right]$ & 2400 & 2450 & 2500 \\
\hline Elastic modulus [GPa] & 5.0 & 10.0 & 15.0 \\
\hline Poisson’s ratio [-] & 0.2 & 0.2 & 0.2 \\
\hline Porosity [\%] & 6.0 & 4.0 & 0.0 \\
\hline Permeability [m/s] & $10^{-5}$ & $10^{-5}, 10^{-6}$ and $10^{-7}$ & $10^{-6}$ and $10^{-7}$ \\
\hline
\end{tabular}


Table 2 - Uplift forces, absolute and relative values normalized by the dam self-weight

\begin{tabular}{|l|c|c||}
\hline \multicolumn{2}{|c|}{ Flow only through the rock mass } \\
\hline \hline \multicolumn{1}{|c|}{ Diagram } & Force [kN] & $\%$ Self-weight \\
\hline Theoretical triangular solution & 3143 & $40 \%$ \\
\hline Uncoupled model & 3593 & $45 \%$ \\
\hline Coupled model (dam impervious) & 3863 & $49 \%$ \\
\hline Coupled full model & 4112 & $52 \%$ \\
\hline With curtain & 3241 & $40 \%$ \\
\hline With drainage & 1928 & $24 \%$ \\
\hline With curtain and with drainage & 1942 & $24 \%$ \\
\hline \hline
\end{tabular}


Table 3 - Flow rates drained by the dam and the foundation

\begin{tabular}{|l|c|c|c|c|}
\cline { 2 - 5 } \multicolumn{1}{c|}{} & $\begin{array}{c}\text { Before } \\
\text { rehabilitation }\end{array}$ & $\begin{array}{c}\text { With } \\
\text { curtain }\end{array}$ & $\begin{array}{c}\text { With } \\
\text { drainage }\end{array}$ & $\begin{array}{c}\text { With curtain } \\
\text { and drainage }\end{array}$ \\
\hline \hline Total flow rate (l/min) & 2150 & 496 & 3070 & 592 \\
\hline \hline Input - Upstream foundation & $0 \%$ & $1 \%$ & $2 \%$ & $2 \%$ \\
\hline Input - Upstream face & $100 \%$ & $99 \%$ & $98 \%$ & $98 \%$ \\
\hline \hline Output - Downstream foundation & $1 \%$ & $2 \%$ & $0 \%$ & $0 \%$ \\
\hline Output - Downstream face & $99 \%$ & $98 \%$ & $36 \%$ & $15 \%$ \\
\hline Output - Drainage system & - & - & $64 \%$ & $85 \%$ \\
\hline
\end{tabular}

